\title{
Relationship between the Knowledge of Benefit of Physical Activity and Physical Activity Level among Individuals with Asthma in Kano State, Nigeria
}

\author{
Ibrahim Ahmad Abubakar*, Aisha Abdulazeez Shitu, Jibril Muhammed \\ Department of Physiotherapy, Faculty of Allied Health Sciences, Bayero University, Kano, NIGERIA.
}

Received: 11 Aug 2019;

Accepted: 01 Oct 2019

*Correspondence to

PT. Ibrahim Ahmad Abubakar (BPT), Department of Physiotherapy, Faculty of Allied Health Sciences, Bayero University, Kano, NIGERIA.

Email: ibrahimcsskd@gmail.com Copyright: (C) the author(s),publisher and licensee Indian Academy of Pharmacists. This is an open-access article distributed under the terms of the Creative Commons Attribution Non-Commercial License, which permits unrestricted non-commercial use, distribution, and reproduction in any medium, provided the original work is properly cited.

\begin{abstract}
Background: Regular physical activity is an important factor in the promotion of health and quality of life among individuals with asthma. There is a dearth of information on the relationship between knowledge of benefit of physical activity and physical activity level among individuals with asthma in Kano State, Nigeria. Aim: To determine the relationship between the knowledge of benefit of physical activity and physical activity level among individuals with asthma in Kano State, Nigeria. Methodology: Seventy-four (74) participants were recruited from two selected hospitals in Kano State in a cross sectional study. International Physical Activity Questionnaire (IPAQ)-short Form and Knowledge Questionnaire were used to collect information on self-reported physical activity in the last 7 days and level of knowledge of benefit of physical activity respectively. Descriptive statistics was used to describe the data and Spearman Rank Correlation test were used to analyze the data at alpha level of 0.05 . Results: A positive relationship existed between overall knowledge of benefit of physical activity and physical activity level among the participants. The majority of the participants were males $43(58.1 \%)$. About 41 (55.4\%) were in the age group of 18-35 years, most of them 32 (43.2\%) were married. Knowledge assessment showed that 56 (75.7\%) of them had low knowledge of benefit of physical activity. Physical activity level assessment revealed that $39(52.7 \%)$ had low physical activity level. Negative relationship was observed between knowledge of benefit of physical activity and all socio-demographic studied (age, gender, marital status, tribe, education and occupation). A positive correlation existed between physical activity level and socio demographic variables (age, gender, marital status and tribe) except that a negative correlation was observed only between physical activity level with education and occupation. Conclusion: Knowledge of benefit of physical activity correlates positively with physical activity level among individuals with asthma in Kano State. Study population had low physical activity and low knowledge of benefit of physical activity.
\end{abstract}

Key words: Physical activity, Physical activity level, Asthma, Knowledge of benefit of physical activity, Relationship, IPAQ.

\section{INTRODUCTION}

Physical activity (PA) is defined as any bodily movement produced by skeletal muscles that requires energy expenditure above resting levels, in addition to heart rate and breathing frequency..$^{[1]}$ The quantity of energy needed to achieve an activity can be measured in kilojoules $(\mathrm{kJ})$ or kilocalories (kcal); $4.184 \mathrm{~kJ}$ is essentially equal to $1 \mathrm{kcal} .{ }^{[2]}$ Physical activity is a complex behaviour influenced by a combination of individual, socio-cultural and environmental factors. ${ }^{\left[{ }^{3}\right]}$ Asthma is characterized by increased responsiveness of the trachea and bronchi and reversible airflow restriction due to airway inflammation and/or airway constriction. ${ }^{[4]} \mathrm{It}$ is a common long term inflammatory disease of the airways of the lungs which is characterized by variable and recurring symptoms, reversible airflow obstruction and bronchospasm. ${ }^{[5]}$ The severity of asthma ranges from mild with intermittent symptoms to severe with persistent symptoms that impact quality of life. An increase in the PA level would possibly provide important health benefits for all age groups in a population level, in terms of increased functionality, reduced risk of disease and overall better quality of life. ${ }^{[6]}$ Risk of death from any cause and from chronic disease is generally highest among the least fit and physically active and lowest among the most fit and physically active. ${ }^{[7]}$ These strong bodies of proof has led to the recommendation that physical activity prescription should become a greater focus of medical school training and primary care physicians should discuss, promote and prescribe physical activity during each patient visit. ${ }^{[8]}$ Despite the benefit of physical activity, Individuals with asthma are less likely to engage in physical activity due to the possibility of eliciting respiratory symptoms, such as coughing, wheezing, dyspnoea and/ or chest tightness ${ }^{[9]}$ which can be a barrier for adoption and maintenance of regular physical activity among those with this disease. Individuals with obstructive respiratory disease tend to avoid physical activity for fear of triggering symptoms. ${ }^{[10]}$ Knowledge is awareness about objects and it has direct impacts on improving task performance. Knowledge, attitude and beliefs about physical activity were identified by Dishman et al. ${ }^{[1]}$ as demographic variables that mediate participation in physical activity. In a study on the level of knowledge of physical activity among Individuals with COPD and/or asthma by Ramanathan $e$ al. showed that out of 70 patients, $55.7 \%$ of them did not try to attempt to know about physical activity, $28.6 \%$ of them had poor knowledge on physical activity. ${ }^{[12]}$ This study also revealed 
that $51.4 \%$ of the subjects preferred not to perform physical activity because of the fear that their condition might become worse due to physical activity. ${ }^{[12]}$ There is a significant gap in patients knowledge about benefit of physical activities and this consequently affects their physical activity level.

Therefore, there is dearth of information on the relationship between the knowledge of benefit of Physical activity and physical level among individuals with asthma in Kano State, Nigeria.

\section{MATERIALS AND METHODS \\ Subjects}

Seventy-four $(n=74)$ participants aged from 18 years and above 60 years of age who were clinically diagnosed with asthma by the hospital physician. Participants were recruited from Muhammad Murtala Specialist Hospital, Kano State and Muhammmad Abdullahi Wase Specialist Hospital, Kano State, Nigeria. Participants with comorbidity that might influence their overall well-being were excluded from this study.

\section{Research design and Sampling Technique}

The research design for this study was a cross-sectional, It is a type of study that gathers/represents information about a population at one point in time and purposive sampling technique was used to recruit participants for this study.

\section{Ethical clearance}

Ethic committee of Kano State Ministry of Health, Nigeria granted ethical approval before the commencement of the study

\section{Instruments}

The instruments used in this study are Consent form, Proforma /Data sheet, International Physical Activity Questionnaire Short Form (IPAQ-SF) and Knowledge of Benefits of Physical Activity Questionnaire.

Proforma/data sheet was used to obtain socio-demographic characteristics of participants which include; gender, age, ethnicity, Educational level, marital status, occupation, Smoking status.

International Physical Activity Questionnaire Short Form (IPAQ-SF) was Wigh level of benefit of Physical activity knowledge (18)

- low level of benefit of physical activity knowledge (56)

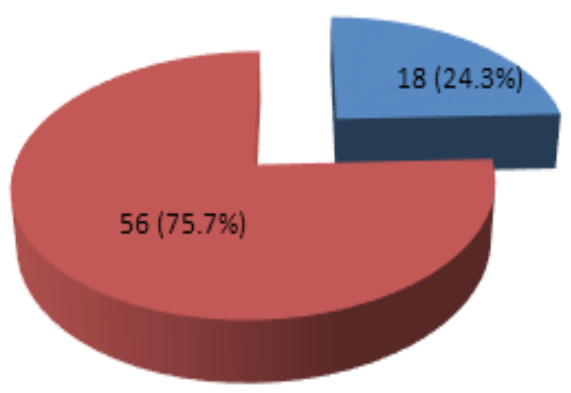

Figure 1: Knowledge of benefit of physical activity used to provide information on how physically active the participants had been in the preceeding seven days. IPAQ is a generic scale and it has a reliability of $(0.66-0.88)^{[13,14]}$ and criterion validity of $0.30 \cdot{ }^{[15]}$ Knowledge of Benefits of Physical Activities Questionnaire was used to provide basic information that the participants possessed regarding Physical activity importance. It was adapted from Chaubal, ${ }^{[16]}$ in his study titled "Effect of Knowledge of Exercise Benefits on Attitude, Motivation and Exercise Participation". The Questionnaire was a self-developed questionnaire with 15 items and a reliability of $(r=0.883)$. Individuals who had a score in the range 38-46 were considered to have a high knowledge score and the individuals who scored below and above this range were considered to have a low knowledge score. ${ }^{[16]}$ All the questionnaires were translated into Hausa language for easy understanding of the participants.

\section{Data analysis}

Descriptive statistics frequency and percentage was used to summarize the data obtained from socio-demographic variables, the physical activity level and as well as knowledge of benefits of physical activity variables. The Spearman Rank Correlation was used to check the relationship between the knowledge of benefit of physical activity level and Socio-demographic variables, it was also used to check the relationship between the physical activity level and Socio-demographic variables

\section{RESULTS}

Seventy-four participants diagnosed with asthma participated in this study. Majority of the participants were males 43 (58.1\%). 41 (55.4\%) were in the age group of $18-35$ years, most of them $32(43.2 \%)$ were married and majority $58(78.4 \%)$ were Hausa by tribe. $25(33.8 \%)$ had the secondary education and $33(44.6 \%)$ were self-employed.

Knowledge of benefit of physical activity among the participants.

The Figure 1 above shows that $56(75.7 \%)$ of the participants had low knowledge of benefit of physical activity while only 18 (23.3\%) of them had high knowledge of benefit of physical activity.

\section{Physical activity level participation among the participants}

In the Figure 2 below, it was observed that among 74 individuals recruited, majority $39(52.7 \%)$ had low level of physical activity, $15(20.3 \%)$ of them

$$
\begin{aligned}
& \text { Low leve I of Physical activity (39) } \\
& \text { Mode rate leve I of Physical activity(15) } \\
& \text { Wigh leve I of Physical activity(20) }
\end{aligned}
$$
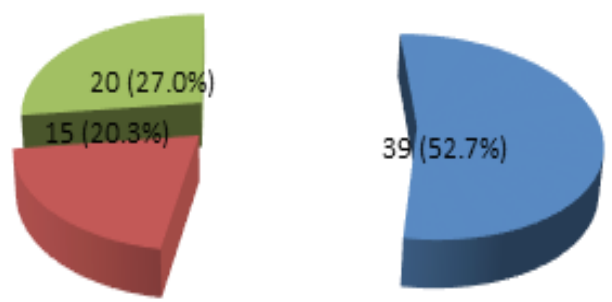

Figure 2: Level of physical activity 
reported a moderate level of physical activity and the remaining $20(27.0 \%)$ had high levels of physical activity.

Relationship between the knowledge of benefit of physical activity and socio-demographic variables among the Participants.

In Table 1, non-significant negative correlation was observed among sociodemographic (gender, marital status, tribe, educational level, occupation) and knowledge of benefit of physical activity among the participants, whereas only age had a significant negative relationship with knowledge of benefit of physical activity.

Relationship between physical activity level and sociodemographic variables among the study sample.

A weak positive correlation was observed between physical activity level and age, gender, marital status and tribe. Educational level and occupation of the participants showed a weak negative relationship with physical activity level (Table 2).

\section{Relationship between the knowledge of benefit of physical activity and physical activity level}

Table 3 showed weak positive correlation between knowledge of benefit of physical activity and physical activity level among the recruited individuals with asthma in Kano State, though not significant.

\section{DISCUSSION}

The purpose of the current was to investigate the relationship between the knowledge of benefit of physical activity and physical activity level among individuals with asthma in Kano State, Nigeria.

In this study, individuals with asthma who met the inclusion criteria were recruited. The ages ranges between 18 to above 60 years, majority of the individuals are in the age group of 18-35 years, forty three of them were males, thirty two are married, About seventy one of the patients had never smoke thus making it similar to a study conducted by Ramanathan et al. ${ }^{[12]}$ on level of knowledge of physical activity among chronic obstructive pulmonary disease and/or asthmatic patients in selected hospital in Malaysia which showed that out of seventy patients the majorities of the individuals were males, Most of them were married.

It was revealed in this study that, majority $56(75.7 \%)$ of them have low knowledge about the benefit of physical activity, this is consistent with the study conducted by Ramanathan et al. ${ }^{[12]}$ Who reported that out of the recruited 70 patients majority $(47 \%)$ of them don't know much about the benefit of physical activity. The individuals have poor knowledge of benefit of physical activity because majority of them (25) in this study attained secondary school and it's not likely for an individual that attained only secondary school to know much about benefit of physical activity.

The findings of this study also showed that among seventy-four patients recruited; most of them had low level physically activity, which was similarly reported by World Health Organization that $15 \%$ of adults with asthma over the age of 31 were found to be physically inactive in 2008 . This may explain why a large percentage of this population remains inactive and are more likely to report "no physical activity". This might not be different from Ramanathan et al. ${ }^{[12]}$ who reported that $51.4 \%$ of the recruited seventy subjects

\begin{tabular}{|l|l|l|}
\hline \multicolumn{3}{|c|}{$\begin{array}{l}\text { Table 1: Relationship between the knowledge of benefit } \\
\text { of physical activity and socio-demographic variables. }\end{array}$} \\
\hline Variables & $\mathrm{r}$ & $p$-value \\
\hline Age & -0.240 & 0.04 \\
\hline Gender & -0.157 & 0.18 \\
\hline Marital status & -0.167 & 0.16 \\
\hline Tribe & -0.008 & 0.95 \\
\hline Educational level & -0.147 & 0.21 \\
\hline Smoking status & 0.117 & 0.32 \\
\hline Occupation & -0.044 & 0.71 \\
\hline
\end{tabular}

${ }^{*}$ significance at $p<0.05$.

\begin{tabular}{|l|l|l|}
\hline \multicolumn{3}{|l|}{$\begin{array}{l}\text { Table 2: Relationship between physical activity level and } \\
\text { socio-demographic variables among the study samples. }\end{array}$} \\
\hline Variables & $\mathbf{r}$ & $p$-value \\
\hline Age & 0.017 & 0.888 \\
\hline Gender & 0.040 & 0.738 \\
\hline Marital status & 0.007 & 0.953 \\
\hline Tribe & 0.135 & 0.252 \\
\hline Educational level & -0.043 & 0.716 \\
\hline Smoking status & 0.101 & 0.394 \\
\hline Occupation & -0.028 & 0.816 \\
\hline
\end{tabular}

\begin{tabular}{|c|c|c|}
\hline Variables & $r$ & $p$-value \\
\hline \multicolumn{3}{|l|}{ Knowledge of benefit } \\
\hline Of physical activity and & 0.034 & 0.773 \\
\hline Physical activity level & & \\
\hline
\end{tabular}

* Significance at $p>0.05$

preferred not to perform physical activity because of the fear that their condition might become worse due to physical activity and this contribute to their physical inactive.

However, this findings were in contrast with the findings of Chaubal $e t a l .{ }^{[16]}$ who reported that out of hundred participants, $38 \%$ of the subjects were moderately active which are the majority, also another study by Stanley et $a l .^{[17]}$ on level of participation and knowledge of physical activity in Hong Kong Chinese adults with asthma and their association with age, they revealed that out of the recruited participants $40.2 \%$ engaged in some sort of activity implying moderate activity and $36.1 \%$ of them were sedentary but $23.7 \%$ participants are physically active. But being their sample size as 207 participants, the result of this study can be conflicting as a result of negligible population.

The results from this study showed that knowledge of benefit of physical activity did not have a significant relationship on the physical activity level among the sample population used in this study. This finding was consistent with the previous studies which reported that knowledge is not one of the primary factors that contribute to physical activity level. ${ }^{[11,17]}$ The result of this study showed that there is weak positive relationship between knowledge of benefit of physical activity and physical activity level indicating that individuals with high knowledge of benefit of physical activity are physically active. 


\section{CONCLUSION}

Individuals with asthma studied were physically inactive and have low knowledge of benefit of physical activity. There is weak insignificant relationship between knowledge of benefit of physical activity and physical activity level among the individuals with asthma in Kano State.

\section{ACKNOWLEDGEMENT}

We wish to acknowledge all the participants of this study for their cooperation throughout the course of the study.

\section{CONFLICT OF INTEREST}

The authors declare no conflict of interest.

\section{ABBREVIATIONS}

PA: Physical activity; IPAQ SF: International physical activity questionnaire short form; COPD: Chronic obstructive pulmonary disease.

\section{REFERENCES}

1. Canadian Society for Exercise Physiology. Csep-Physical Activity Training for Health (Csep-Path). Canadian Society for Exercise Physiology. 2013.

2. Davidson S, Passmore R, Brook JF, Truswell AS. Human nutrition and dietetics. Ed. 7. Churchill Livingstone, New York. 1979.

3. Watz H, Waschki B, Meyer T. Physical Activity in Patients with Copd. European Respiratory Journal. 2009;33(2):262-72.

4. Eleventh revision of the International Classification of Diseases. World Health Organization. 2017. https://icd.who.int.

5. National Heart, Lung and Blood Institute [NHLBI]. Guidelines for the Diagnosis of Management of Asthma. 2007. https://www.nhlbi.gov>health

6. Boreham C, Riddoch C. The physical activity, fitness and health in children. Journal of Sports Sciences. 2001;19(12):915-29.

7. Warburton DER, Nicol CW, Bredin SSD, et al. Health benefits of physical activity: The evidence. CMAJ. 2006;174(6):801-7.
8. Khan MY, Shatoor AS, Mahfouz AA. Nutrition, physical activity and gender risks for adolescent obesity in southwestern Saudi Arabia. Saudi J Gastroenterol. 2011;17(5):318-22. ncbi.nlm.nih.gov

9. Mancuso CA, et al. Barriers and Facilitators to Healthy Physical Activity in Asthma Patients. Journal of Asthma. 2006;43(2):137-43.

10. Amorim PB, et al. Barriers Associated with Reduced Physical Activity in Copd Patients. Jornal Brasileiro De Pneumologia. 2014;40(5):504-12.

11. Dishman RK, Sallis JF. Determinants and interventions for physical activity and exercise. Physical activity, fitness and health: International proceedings and consensus statement. Champaign, IL, England: Human Kinetics Publishers. 1994;214-38.

12. Ramanathan K, Lee SY, Wong S, et al. A Descriptive study on level of knowledge of physical activity among chronic obstructive pulmonary disease patients in selected hospital in Malaysia. American Journal of Advances in Medical Science. 2015;3(4):27-31.

13. Craig C L, Marshall AL, Sjostrom M, Bauman AE, Booth ML, Ainsworth BE, et al. International Physical Activity Questionnaire: 12-country reliability and validity. Medicine and Science in Sports and Exercise. 2003;35(8):1381-95. PubMed doi:10.1249/01.MSS.0000078924.61453.FB

14. Deng HB, Macfarlane DJ, Thomas GN, Lao XQ, Jiang CQ, et al. Reliability and validity of the IPAQ-Chinese: The Guangzhou Biobank Cohort study. Medicine and Science in Sports and Exercise. 2008;40(2):303-7. PubMed doi:10.1249/ mss.0b013e31815b0db5

15. Pate RR, Pratt M, Blair SN, et al. Physical activity and public health: A recommendation from the Centers for Disease Control and Prevention and the American College of Sports Medicine. Jama. 1995;273(5):402-7.

16. Chaubal SR. Effect of Knowledge of Exercise Benefits on Attitude, Motivation and Exercise Participation. 2011;1-58.

17. Stanley $\mathrm{S}$, Chuen $\mathrm{H}$, et al. Level of participation and knowledge of physical activity in Hong Kong Chinese adults and their association with age. Journal of Aging and Physical Activity. 2001;9(7):372-85.

18. Trost SG, Owen NN, Bauman AE, Sallis JF, Brown WW. Correlates of adults' participation in physical activity: Review and update. Medicine and Science in Sports and Exercise. 2001;34(12):1996-2001.

Cite this article as: Abubakar IA, Shitu AA, Muhammed J. Relationship between the Knowledge of Benefit of Physical Activity and Physical Activity Level among Individuals with Asthma in Kano State, Nigeria. J Pharm Pract Community Med. 2019;5(3):54-7. 